\title{
RESENHA
}

\section{RESENHA DO LIVRO: APRENDIZAGEM MULTIMÍDIA}

André Coelho da Silva*

\begin{tabular}{r|} 
*Doutor em Educação pela \\
Universidade Estadual de Campinas \\
(Unicamp). Professor do Instituto \\
Federal de São Paulo (IFSP), campus \\
Itapetininga. Grupo de Pesquisas \\
sobre Formação de Professores \\
para o Ensino Básico, Técnico, \\
Tecnológico e Superior (FoPeTec). \\
Itapetininga, SP - Brasil. \\
Email:< <andrecoelho@ifsp.edu.br >
\end{tabular}

MAYER, Richard E. Multimedia Learning, 2a ed. New York: Cambridge University Press, 2009.

Richard Mayer é professor de Psicologia na Universidade da Califórnia desde 1975. Seus interesses de pesquisa estão relacionados à aplicação da ciência da aprendizagem à educação e envolvem, especialmente, estudos sobre cognição, tecnologia e ensino. Atualmente desenvolve projetos sobre aprendizagem multimídia, aprendizagem apoiada por computador e uso de jogos computacionais para a aprendizagem. Nesse sentido, tem como objetivo central encontrar formas de auxiliar as pessoas a desenvolverem aprendizagens que permitam a utilização desses conhecimentos em novas e diferentes situações.Mayer é autor de mais de 500 trabalhos, entre eles, livros como: Jogos computacionais para a aprendizagem (Computer Games for Learning, 2014), Aplicando a ciência da aprendizagem (Applying the Science of Learning, 2011) e Manual da Aprendizagem Multimídia de Cambridge (The Cambridge Handbook of Multimedia Learning: Second Edition, 2014).

No livro Aprendizagem Multimídia (Multimedia Learning, 2009) Mayer visa apresentar princípios para a produção de recursos didáticos multimídia que possam favorecer uma melhor aprendizagem.

Para o autor, um recurso multimídia não é um meio utilizado para trabalhar determinados conteúdos (livros, computadores etc.), mas sim um material que engloba palavras (texto falado ou escrito) e informações gráficas/figuras (gráficos, fotos, animações, mapas etc.). Assume-se que os meios não possuem relação direta com a aprendizagem e, portanto, ao invés de buscar meios que potencialmente maximizariam a aprendizagem, a questão passa a ser como desenvolver recursos multimídia que possam aperfeiçoar os conteúdos/mensagens abordados.

Mayer distingue dois tipos de abordagem quanto à produção de recursos multimídia: a centrada na tecnologia e a centrada nos aprendizes. Enquanto a primeira objetiva possibilitar o acesso às novas tecnologias implicando na necessidade de que os aprendizes se adaptem a elas; a segunda visa adaptar as novas tecnologias 
às necessidades dos aprendizes visando favorecer a aprendizagem. A abordagem centrada nos aprendizes - assumida por Mayer no livro - partiria da tentativa de entender o funcionamento da cognição humana. Além disso, recursos coerentes com tal funcionamento seriam mais efetivos na promoção da aprendizagem.

A cognição humana poderia ser resumida em dois pressupostos: I) o do canal duplo, que indica a existência de dois sistemas não-equivalentes de processamento de informação: verbal/auditivo e visual/pictórico; e II) o da capacidade cognitiva, que indica que a quantidade de informação processada simultaneamente em cada canal é limitada. O resultado de um processamento cognitivo ativo seria a produção de um modelo mental. Nesse contexto, aprender implicaria em lembrar, isto é, em ser capaz de reproduzir e reconhecer o conteúdo, e em entender, isto é, em construir um modelo mental coerente para o conteúdo. Consequentemente, aprendizagem multimídia seria a construção de conhecimento (enquanto algo pessoal, intransferível) a partir da interação com um recurso multimídia.

Para que resulte em aprendizagem multimídia, a interação com o recurso precisaria desencadear uma série de processos: seleção de palavras relevantes para processamento na memória de trabalho verbal; seleção de imagens relevantes para processamento na memória de trabalho visual; organização das palavras de forma coerente em um modelo mental verbal; organização das imagens de forma coerente em um modelo mental visual; integração das representações verbais e visuais entre si e com o conhecimento prévio.

Mayer apresenta alguns princípios que poderiam auxiliar no desenvolvimento de recursos didáticos multimídia - de forma a torná-los potencialmente mais efetivos em termos da aprendizagem: I) Concentração (destacar ideias chave nas figuras e textos); II) Concisão (minimizar detalhes desnecessários/alheios nos textos e figuras); III) Correspondência (colocar figuras e textos correspondentes próximos); IV) Concretude (apresentar textos e figuras de maneira a facilitar a visualização); V) Coerência (construir uma linha de raciocínio e uma estrutura clara); VI) Compreensibilidade (utilizar textos e figuras familiares); e VII) Codificabilidade (utilizar textos e figuras cujas características chave facilitem a memorização). De fato, tais princípios são encampados pelos doze princípios da aprendizagem multimídia definidos pelo autor (entendidos como princípios para a produção de materiais multimídia).

Os princípios da aprendizagem multimídia são consistentes com o funcionamento da cognição e da aprendizagem humana e estão amparados em resultados de diversos estudos empíricos focados em testes de transferência, isto é, testes que implicam em utilizar o conhecimento para resolver problemas novos/diferentes.

Cinco princípios visam reduzir o processamento desnecessário/alheio, evitando sobrecarga cognitiva. O princípio da coerência indica que as pessoas aprendem melhor quando informações (palavras, figuras, símbolos, sons, músicas etc.) desnecessárias/alheias são excluídas. O princípio da sinalização sugere que as pessoas aprendem melhor quando a organização do material é explicitada, pois o aprendiz poderia ser guiado ao que é essencial, favorecendo a organização mental. O princípio da redundância afirma que as pessoas aprendem melhor com desenhos e narração do que com desenhos, narração e texto escrito (legenda 
do que está sendo narrado) - caso que implicaria em sobrecarga do canal visual. O princípio da contiguidade espacial indica que as pessoas aprendem melhor quando as palavras e as figuras correspondentes estão espacialmente próximas. Já o princípio da contiguidade temporal sugere que as pessoas aprendem melhor quando palavras e imagens correspondentes aparecem ao mesmo tempo. Esses dois últimos princípios estão embasados na ideia de que a contiguidade espacial/ temporal favorece o estabelecimento de conexões entre as informações verbais e visuais (será gasto menos recurso cognitivo no estabelecimento dessas conexões).

Três princípios visam favorecer a administração do processamento essencial, isto é, o responsável por representar o material na memória de trabalho. Em caso de sobrecarga no processamento essencial, restariam poucos recursos cognitivos para realizar o processamento gerador, responsável por organizar e integrar as representações mentais produzidas. Segundo o princípio da segmentação as pessoas aprendem melhor quando o recurso é apresentado em unidades sequenciais nas quais o usuário pode definir o ritmo (ideia de que cada sujeito tem um tempo diferente de processamento). Segundo o princípio do pré-treinamento as pessoas aprendem melhor quando já sabem os nomes e as características dos principais conceitos antes de entrar em mais detalhes. O princípio da modalidade sugere que as pessoas aprendem melhor com figuras e textos falados do que com figuras e textos escritos. A razão é que textos escritos podem competir com as figuras no canal visual.

Quatro princípios visam promover o processamento gerador. O princípio multimídia afirma que as pessoas aprendem melhor com palavras e figuras do que só com palavras. Trata-se de um princípio que justifica o livro como um todo. O princípio da personalização sugere que as pessoas aprendem melhor quando as palavras estão em estilo conversacional do que em estilo formal. Por fim, os princípios da voz e da imagem são extensões do princípio da personalização e, segundo Mayer, quando da publicação do livro, ainda estavam em fase de estudos preliminares. Segundo o princípio da voz, as pessoas aprendem melhor quando a voz da narração é humana do que quando a voz é de máquina. Já segundo o princípio da imagem, as pessoas não necessariamente aprendem melhor quando a imagem de quem está falando/narrando está na tela.

Apontamos como os principais pontos positivos do livro: i) a forma didática e sistemática como o autor discute suas considerações, sempre fazendo recapitulações, explicitando seus objetivos de maneira clara e organizando as informações em tabelas quando possível; ii) a consideração de que os princípios da aprendizagem multimídia não são regras universais; iii) a fundamentação teórica e o amplo número de estudos empíricos que embasam os princípios. Nesse sentido, trata-se de um livro que oferece implicações relevantes para a área de pesquisa em ensino de ciências como um todo e, especificamente, para pesquisadores que atuam na produção de recursos didáticos multimídia (pesquisadores associados ao estudo das tecnologias de informação e comunicação, por exemplo) ou que buscam compreender o funcionamento, os limites e as possibilidades da utilização de recursos desse tipo no ensino e na aprendizagem de ciências.

De fato, é possível associar a temática do livro a, ao menos, duas das linhas temáticas do último Encontro Nacional de Pesquisa em Educação em Ciências (XI ENPEC), realizado em julho de 2017: "Processos e materiais educativos 
em Educação em Ciências" e "Tecnologias da informação e comunicação em Educação em Ciências". Entendemos que a presença dessas linhas temáticas no mais importante evento brasileiro da área de ensino de ciências evidencia que a produção, a validação e a utilização de recursos didáticos em situações de ensino e aprendizagem, seja em contextos de pesquisa ou não, costumam se constituir como atividades recorrentes na atuação dos professores e pesquisadores dessa área. Logo, sugerimos que os princípios caracterizados por Mayer podem funcionar como aporte teórico-metodológico para o desenvolvimento dessas atividades, especialmente no que se refere ao projeto e à construção de recursos didáticos multimídia.

Em contraposição aos muitos pontos positivos do livro, pensamos ser necessário apontar também que, embora comente sobre os testes empíricos realizados, Mayer não indica quantos alunos participaram de cada teste, tampouco detalha as condições de aplicação de cada um deles. Vale frisar ainda que os testes foram realizados utilizando a metodologia de grupos controle e grupos experimentais, a qual pode ser alvo de críticas tendo em vista a complexidade envolvida nos atos educacionais - desconsiderada por tal metodologia. Outro aspecto que talvez pudesse ser mais explorado no livro é a discussão de possíveis exceções individuais no que diz respeito aos testes empíricos realizados. Tal possibilidade, no entanto, parece não condizer com a abordagem quantitativaestatística adotada pelo autor na obra.

Em síntese, apesar de ter sido publicado em língua inglesa, a leitura do livro é agradável e simples. Recomendamo-la especialmente aos interessados em elementos associados à aprendizagem e ao uso/estudo de recursos multimídia no ensino.

\section{BIBLIOGRAFIA E SUGESTÕES DE LEITURA}

MAYER, R. E. Applying the science of learning. Upper Saddle River: Pearson, 2011.

MAYER, R. E. Computer games for learning: An evidence-based approach. Cambridge: MIT Press, 2014.

MAYER, R. E. The Cambridge handbook of multimedia learning. New York: Cambridge University Press, 2014.

UCSB - UNIVERSITY OF CALIFORNIA, SANTA BARBARA. Richard Mayer. Department of Psychological \& Brain Sciences, s/d. Disponível em: <https://www.psych. ucsb.edu/people/faculty/mayer>. Acesso em: 09 ago. 2016.

Submetido em 09/08/2016

Aprovado em 17/11/2017

\section{Contato:}

Instituto Federal de Educação, Ciência e Tecnologia de São Paulo (IFSP)

Campus Itapetininga

Avenida João Olímpio de Oliveira, 1561 - Vila Asem

CEP 18.202-000 - Itapetininga, SP - Brasil 